\title{
THE EFFECT OF COGNITIVE APPRENTICESHIP AND KELLER'S PLAN ON LEARNING PASSING FROM TOP IN VOLLEYBALL
}

\author{
Wissam Salman Ahmed \\ Prof.Dr. GhadaMoayadShihab \\ University of Baghdad / College of Physical Education and Sports Sciences
}

DOI: $10.37648 / \mathrm{ijrssh.v10i01.018}$

Received:04 $4^{\text {th }}$ October 2019; Accepted:23 ${ }^{\text {rd }}$ November, 2019; Published: $04^{\text {th }}$ December, 2019

\begin{abstract}
:
Cognitive apprenticeship and individualization of education methods of education that may be appropriate and that have a positive impact in the education of volleyball skills as each method of privacy in learning has been the goal of research to identify the impact of cognitive apprenticeship and Keller plan in learning the skill of passing from the highest in volleyball The first two students of the middle class have assumed that there are statistically significant differences between the pre and post tests of the three research groups in learning the skill of passing from the top in volleyball, and that there are statistically significant differences in the post tests in the research sample, was used The experimental method in the method of three groups (experimental and control) and the sample was the first grade students in the medium Mohammed Baqir al-Sadr for boys / Baghdad / Karkh third, the number of (112) students used the cognitive apprenticeship method with the first experimental group and the method of the Keller plan with the second experimental group and the Ameri method With the control group and after the collection of data and statistical processing was reached a group of conclusions, the most important methods of cognitive apprenticeship and Keller plan (individualization of education) have an effective impact on the research variables compared to the method used.

Keywords: / Cognitive Discipleship - Keller Plan.

INTRODUCTION

The rapid developments and the accompanying progress in the fields of knowledge imposed on us a vital requirement in the learning process, which is the methods of learning and the importance and need for them and their positive role in educational outputs as educational trends emphasize the achievement of selflearning of the student, which is the basic building

block in the community building and the educational process that Centered pupil and teacher together.

Volleyball is a team game whose skills are somewhat difficult for beginners, especially among middle school students and need to anticipate and react appropriately to the opponent's movement, which requires systematic planning and the use of appropriate and effective teaching methods that develop the ability of beginners to learn better.
\end{abstract}


(IJRSSH) 2020, Vol. No. 10, Issue No. I, Jan-Mar

The researchers believe that the cognitive apprenticeship and individualization of education methods of education that may be appropriate and that have a positive impact in the teaching of volleyball skills as each method of privacy in learning and cognitive apprenticeship of methods in which the role of the student is an initiator and effective and seeking solutions on his own and based on The basis of student work in groups and teams and acquire cognitive skills through cooperative participation through six educational stages (modeling - refinement - meditation - the application of skill - expression - exploration)

The method of individualization of Keller's education is one of the important methods that take into account the individual differences between learners and gives the learner the opportunity to learn according to his own abilities, ie, self-education is independent and based on prepared and complete educational materials to facilitate the learning process, The characteristics of the learners, the curriculum and the desired objectives are reached in accordance with the material and human potential available. "(Abdel-Hafiz, 2000: p. 52)

The aim of the research was to identify the effect of the cognitive apprenticeship and Keller plan in learning the skill of passing from the top in volleyball in first grade students. The researchers hypothesized that there are statistically significant differences between the pre and post tests of the three research groups in learning the skill of passing from the top in the ball. There are statistically significant differences in the post tests in the research sample.

\section{MATERIALS AND METHODS:}

Place of study: Mohammed Baqir al - Sadr Medium Stadium for boys Baghdad / Karkh 3.

Experimental Design: The experimental method was used to design the three groups (experimental and control) with pre- and post-test to suit the research problem. Three exploratory experiments were conducted. The first exploratory experiment was for the skill test which was conducted on Monday (18/2/2019) on the sample The first exploratory experiment on cognitive apprenticeship and the third on the method of individualization of education was conducted on Tuesday (19/2/2019). Then the pre-test of the research sample was conducted on Wednesday
e-ISSN: 2249-4642, p-ISSN: 2454-4671

and Thursday on (20-21 / 2/2019) after giving a module on skills for each group of time (30) to take an idea about the skills, the main experiment was applied in the second semester of (2018- It took the implementation of educational units for (two months and a week) from (24/2/2019) until (5/5/2019) by (2) educational units and two educational units each week and for the three groups as the time of educational presence (45) minutes Which consists of three sections and the work of the researcher in the main section, which has a time (30 d) of the educational unit was teaching the motor skills of the experimental group According to the first cognitive apprenticeship method as follows:

- Modeling: At this stage the teacher of the material explained the skill and presented with a focus on the details of the skill accurately.

- Refinement: Ask a set of questions about the skill by the teacher and ask students to answer them with praise for the best answer and the teacher provided assistance in a timely manner for students to be able to accomplish the task and when the learner reached enough capacity to answer the questions correctly stopped assistance and began to increase Difficult questions The role of the teacher is roaming between groups.

- Application of the skill: the skill was performed by the students. The role of the teacher is to monitor the performance of students in the implementation of educational tasks and evaluate their performance and encourage the best group and the group that showed outstanding performance was given reinforcing feedback, which shows low performance was given corrective feedback.

- Reflection: The stage of the teacher to re performance performance in front of students again and each student to compare his performance with the performance of the teacher to identify the mistakes committed during the application of the skill.

- Expression: Each student expressed and clarified the results of performance orally as one of the students in a group to provide a question on the skill was answered by the groups with the correction of error and praise for the correct answer.

- exploration: The right performance was achieved through a written test through a set of questions to ask the student about the skill was answered, and the 
(IJRSSH) 2020, Vol. No. 10, Issue No. I, Jan-Mar

evaluation of all the views put forward in the previous stages by the teacher.

The second experimental group, which learns the basic skills in the method of individualization of learning, was as follows:

- The researcher has prepared the student's guide to guide the learner through the educational unit, which contains the basic skills, which is the skill of passing from the top in volleyball, explaining the sections of the skill and common mistakes and exercises used and self-evaluation questions that relate to each skill.

- Each student has learned the skill according to his own ability by relying on printed evidence.

- At the end of each educational unit there are tests provide feedback to the learner as the teacher relied on the standard spoken by $80 \%$ relied on for the purpose of transition to another skill, and this was done through short tests skill test and cognitive test paper and pen includes questions prepared in advance in the guide.

The control group was taught the skills according to the style of the teacher.

After the completion of the implementation of the educational units were conducted after the tests of the skill of passing from the top and on the date (7/5/2019).

Skill test:

Repetition test on the wall (Hassanein, Abdel Moneim, 1997; p. 230)

Purpose of the test:

Measuring the ability of the laboratory to pass speed and the amount of skill to pass from the top with fingers, and this test is one of the most appropriate tests for the beginners and beginners.

Tools:

A volleyball, a stopwatch, a smooth wall with a parallel line to the ground and a height of $3 \mathrm{~m}$ from the ground, draws a line parallel to the wall on the ground and is $180 \mathrm{~cm}$ away.

:Performance Specifications

The laboratory stands behind the line that is $180 \mathrm{~cm}$ away from the wall (the scroll line), holding the ball with the hands in front of the face and then scrolling towards the wall and the top of the line on it. This work for half a minute $(30 \mathrm{w})$.

:the conditions
e-ISSN: 2249-4642, p-ISSN: 2454-4671

Scrolling at all times of performance from behind the line scroll -

.The scroll must be above the line on the wall -

.The calculation of time starts from the first pass for a period of 30 seconds -

.- at the beginning of the test must hold the ball with the hands in front of the face and then perform the scrolling with fingers.

- If the ball out of the wall, or touched the wall below the line drawn on the wall, and bounced in a way that made the laboratory continue to pass in front of the scroll line in all these cases on the laboratory hold the ball and re-start the same way the beginning of the test. - must use the skill of passing from the top with fingers and other types of other passes.

- The laboratory shall discontinue performance as soon as the judgment expires the prescribed 30-second period.

Registration: Calculates the number of times the ball touches the wall within (30) seconds of the test, and does not count any attempt to violate the conditions mentioned above, and the final score is the number of valid attempts in the (30) seconds multiplied by 3 and should be noted not to calculate the balls passing at the beginning of the test or pass Following each stop as a result of an error made by the lab.

Research sample: The research community was chosen by the deliberate method of first grade students in Mohammed Baqir al-Sadr medium for boys / Baghdad / Karkh third, numbering (112) students divided into three divisions (A, B, C), and by lot was selected (15 (45) students from $(40.17 \%)$ of the research community.

-Tools used: Arabic and foreign sources and references, Internet, personal interviews with experts and specialists. Data recording and unloading form, performance evaluation form, legal volleyball court, Canon video camera (1), stand Triple cameras (2), laptop computer type (DELL) (1) volleyball balls (15), stopwatch to measure time, whistle (3).

\section{:Statistical means}

SPSS statistical package was used to process the research data. 


\section{RESULT AND DISCUSSION:}

Presentation and analysis of the results of the pre and post tests of the three research groups in the skill tests.

Table (1)

Shows the mean, standard deviation, and test $(\mathrm{C})$ of the three research groups in the pretest and post tests of passing skill from above.

\begin{tabular}{|c|c|c|c|c|c|c|c|c|c|}
\hline \multirow{2}{*}{$\begin{array}{l}\text { Differ } \\
\text { ence }\end{array}$} & \multirow{2}{*}{$\begin{array}{l}\text { Moral } \\
\text { significa } \\
\text { nce }\end{array}$} & \multirow{2}{*}{$\begin{array}{l}(\mathrm{t}) \\
\text { calculated }\end{array}$} & \multirow[t]{2}{*}{$\mathrm{fh}$} & \multirow[t]{2}{*}{$\mathrm{f}$} & \multicolumn{2}{|l|}{ Post test } & \multicolumn{2}{|l|}{ Pre-test } & \multirow[t]{2}{*}{ Variables } \\
\hline & & & & & $\begin{array}{l}\text { standard } \\
\text { deviation }\end{array}$ & $\begin{array}{l}\text { Arithmetic } \\
\text { mean }\end{array}$ & $\begin{array}{l}\text { standard } \\
\text { deviation }\end{array}$ & $\begin{array}{l}\text { Arithmetic } \\
\text { mean }\end{array}$ & \\
\hline moral & .000 & 29.580 & .169 & 5.000 & .516 & 7.466 & .516 & 2.466 & $\begin{array}{l}\text { Experimental } \\
\text { group } 1\end{array}$ \\
\hline moral & .000 & 20.494 & .195 & 4.000 & .487 & 6.666 & 487 & 2.666 & $\begin{array}{l}\text { Experimental } \\
\text { group } 2\end{array}$ \\
\hline moral & .000 & 12.649 & .210 & 2.666 & .560 & 5.200 & .516 & 2.533 & Control group \\
\hline
\end{tabular}

Significant $(<0.05)$ at freedom degree $(14)$

Table (2)

Shows the arithmetic media, standard deviations, mean square deviations, the value of (q) calculated between the three totals and the type of difference in passing skill from the top

\begin{tabular}{|c|c|c|c|c|c|c|c|c|}
\hline $\begin{array}{l}\text { Type of } \\
\text { difference }\end{array}$ & $\begin{array}{l}\text { True } \\
\text { moral }\end{array}$ & $\begin{array}{l}\text { Calculated } \\
\text { value (f) }\end{array}$ & $\begin{array}{l}\text { Average } \\
\text { squares } \\
\text { within } \\
\text { groups }\end{array}$ & $\begin{array}{l}\text { Average } \\
\text { squares } \\
\text { between } \\
\text { groups }\end{array}$ & deviation & the middle & Groups & Skills \\
\hline \multirow{3}{*}{ moral } & \multirow{3}{*}{.000} & \multirow{3}{*}{72.60} & \multirow{3}{*}{11.467} & \multirow{3}{*}{39.644} & .5164 & 7.466 & First Experiment & \multirow{3}{*}{$\begin{array}{l}\text { Transmitte } \\
\mathrm{r} \text { from the } \\
\text { bottom }\end{array}$} \\
\hline & & & & & .4879 & 6.666 & Second pilot & \\
\hline & & & & & .5606 & 5.200 & Control & \\
\hline
\end{tabular}

Significant at (0.05) at freedom degree (42.3)

Table (3)

Shows the results of L.S.D test to find the least significant difference of passing skill from above

\begin{tabular}{|l|l|l|}
\hline M officer & M 2 experimental & Groups \\
\hline $2.26667^{*}$ & $.80000^{*}$ & M 1 experimental \\
\hline $1.46667^{*}$ & & M 2 experimental \\
\hline
\end{tabular}

In the light of the results of the analysis of variance shown in Table (1) and the results of the least significant difference (LSD) shown in Table (3) the presence of statistically significant differences between the three groups in learning the skills in question and for the benefit of the first experimental group (cognitive apprenticeship) followed by the second experimental group) The researcher attributes that the cognitive apprenticeship method gives students an opportunity to discuss and dialogue with colleagues in the same group by working in groups and developing a spirit of cooperation and teamwork, as well as the role of the teacher in mentoring and monitoring the performance of students in the implementation of assignment and support when Impressive In order to increase the level of understanding, the role of the teacher was positive and facilitating the process of learning and not only indoctrinated information. "Learning is a humane process that provides physical and psychological conditions that help the learner to interact actively with the elements of the environment in a specific situation. The duty of teachers is not confined to the classroom, but exceeded outside and became a teacher can not succeed in his work unless it 
turns out the nature of his students and their characteristics and be able to manage the class and take into account the differences between them and encourage them and know their abilities and needs and work on To satisfy them. " (Hariri, 2010: p. 20)

The cognitive apprenticeship method provided an opportunity for the student to obtain information through communication with the teacher and peers within the group as well as the opportunity to discuss the details of the skill that is unclear and increased their motivation to learn and attention to the skill, which made the learning process lively and energetic as the "diversity of teaching methods It allowed the student to be an active element in the educational process by making it able to guide its mental processes and this was a critical element in achieving successful learning. " (Mahmoud, 2016: p. 83) In light of the results, the researchers concluded the following:

- The results in the post-tests showed a clear development of the three research groups (experimental and control) in learning the skill of passing from the top compared with the tribal tests.

- The cognitive apprenticeship and Keller plan (individualization of education) have an effective effect in learning the skill of passing from the top compared to the method used in the lesson and this is evident in the arithmetic circles that appeared in the post-tests for each group.

- The first experimental group (cognitive apprenticeship) surpasses the first experimental group (Keller plan) in learning the skill of passing the highest in volleyball.

\section{REFERENCES:}

Salama Abdel-Hafez; Teaching Aids and Curriculum, Amman, 2000. -

- Rafidah Al-Hariri: Teaching Methods between Tradition and Innovation, I 1, Dar Al-Fikr for Publishing and Distribution Jordan, 2010.

- Doaa Ahmed Mahmoud; the impact of the method of Van Hill on the patterns of brain control in learning some motor skills in the artistic gymnastics for women, Master Thesis, College of Physical Education, University of Baghdad, 2016.

- Mohamed SobhyHassanein and Hamdi AbdelMoneim; Scientific Foundations of Volleyball and Measurement Methods for Evaluation, Physical Skills, Cognitive and Analytical Psychology, 1st Floor, Cairo, The Book Center for Publishing, 1997.

\section{ANNEX (1)}

It shows a model of learning unit according to the cognitive apprenticeship learning style

First experimental group

First Week Date: 24/2/2019

Grade: First Average time: 45 minutes

Educational Objective: Teaching the skill of scrolling from above

\begin{tabular}{|l|l|l|l|l|}
\hline Notes & $\begin{array}{l}\text { Regulatory } \\
\text { side }\end{array}$ & Method of implementation & Time & Section \\
\hline $\begin{array}{l}\text { Emphasis on attendance } \\
\text { and order }\end{array}$ & $\mathrm{XXXXX}$ & $\begin{array}{l}\text { Introduction: (2) d, to take attendance and create } \\
\text { tools. } \\
\text { General warming: (4) d, general preparation of all } \\
\text { body parts. } \\
\text { Special warm-up: (4) d, give a set of exercises for } \\
\text { motor skill. }\end{array}$ & $\begin{array}{l}\text { Preparatory } \\
\text { section }\end{array}$ \\
\hline
\end{tabular}




\begin{tabular}{|c|c|c|c|c|}
\hline & $\begin{array}{l}\text { X XXXXX } \\
\text { X XXX } \\
\text { X XXX }\end{array}$ & $\begin{array}{l}\text { - Modeling: The skill will be explained in detail by } \\
\text { the teacher of the material and presented by the } \\
\text { teacher of the material or model through video and } \\
\text { focus on the details of the skill accurately. } \\
\text { - Refinement: Ask a set of questions by the teacher } \\
\text { about the skill and ask students to answer them with } \\
\text { praise for the best answer and the teacher provides } \\
\text { assistance in a timely manner so that they can } \\
\text { accomplish the task. } \\
\text { - application of skill: the performance of the skill by } \\
\text { the students, the role of the teacher is to monitor the } \\
\text { performance of students in the implementation of } \\
\text { educational tasks and evaluate their performance and } \\
\text { encourage the best group and the group that showed a } \\
\text { distinct performance is given a reinforcing feedback, } \\
\text { which shows low performance given corrective } \\
\text { feedback. } \\
\text { - Reflection: The model is re-presented to the students } \\
\text { a second time and each student compares his } \\
\text { performance with the performance of the model to } \\
\text { identify the mistakes he made during the skill training. } \\
\text { - Expression: The student to express and clarify the } \\
\text { results of performance orally as one of the students in } \\
\text { one of the groups to submit a question on the skill is } \\
\text { answered by the groups with praise for the correct } \\
\text { answer. } \\
\text { - Exploration: The right performance is achieved } \\
\text { through the work of a written test through a set of } \\
\text { forward in the previous stages by the teacher. }\end{array}$ & $\begin{array}{l}30 \mathrm{~m} \\
5 \mathrm{~m}\end{array}$ & $\begin{array}{l}\text { Main section } \\
\text { Bawshar } \\
\text { Educational } \\
\text { aspect }\end{array}$ \\
\hline $\begin{array}{lr}\text { Emphasize optimal } \\
\text { performance } \\
\text { subsequent units }\end{array}$ & X XXXX & Exercises calm him and leave & $5 \mathrm{~m}$ & Final Section \\
\hline
\end{tabular}

\section{ANNEX (2)}

Model of learning unit according to the method of individualization of learning (Keller plan)

Second experimental group

Second Week Date: 25/2/2019

Grade: First Average time: 45 minutes

Educational Objective: Teaching the skill of passing from the top Educational objective: self-reliance and responsibility

\begin{tabular}{|l|l|l|l|l|}
\hline Notes & Regulatory side & Method of implementation & Time & Section \\
\hline $\begin{array}{l}\text { Emphasis on attendance } \\
\text { and order }\end{array}$ & $\mathrm{XXXXX}$ & $\begin{array}{l}\text { Introduction: (2) d, to take attendance and } \\
\text { create tools. }\end{array}$ & $\begin{array}{l}10 \mathrm{~m} \\
\text { section }\end{array}$ \\
\hline
\end{tabular}




\begin{tabular}{|c|c|c|c|c|}
\hline & & $\begin{array}{l}\text { General warming: (4) d, general } \\
\text { preparation of all body parts. } \\
\text { Special warm-up: (4) d, give a set of } \\
\text { exercises for motor skill. }\end{array}$ & & \\
\hline $\begin{array}{l}\text { Emphasize the correct } \\
\text { performance } \\
\text { Give skill-related } \\
\text { feedback }\end{array}$ & $\begin{array}{l}\text { X XXXXX } \\
\text { X XXX } \\
\text { X XXX }\end{array}$ & $\begin{array}{l}\text { skill is presented by the teacher. } \\
\text { Each student will be trained in his / her } \\
\text { own skill and practice based on his / her } \\
\text { own speed based on the printed manual }\end{array}$ & $30 \mathrm{~m}$ & $\begin{array}{l}\text { Main section } \\
\text { Bawshar } \\
\text { Educational } \\
\text { aspect } \\
\text { Applied side }\end{array}$ \\
\hline $\begin{array}{lr}\text { Emphasize optimal } \\
\text { performance in } \\
\text { subsequent units }\end{array}$ & X XXXX & Exercises calm him and leave & $5 \mathrm{~m}$ & Final Section \\
\hline
\end{tabular}

